\title{
Radiodifusión Mapuche en Gulumapu (Chile): formatos y contenidos temáticos para disputar la autorepresentación
}

\author{
Mapuche Broadcasting in Gulumapu (Chile): \\ Issues and Formats for Disputing Self-Representation
}

\author{
Claudia Villagrán Muñoz \\ Doctora en Estudios Latinoamericanos y Maestra en Estudios Políticos y Sociales, Universidad Nacional \\ Autónoma de México - UNAM. \\ cleovi@hotmail.com
}

Resumen Los pueblos indígenas latinoamericanos no sólo han sido marginados y excluidos, sino que también han sido folclorizados por las representaciones sociales y omitidos o tergiversados por los medios de comunicación masivos. Ante ello, la radiodifusión ha sido una herramienta trascendental para la transmisión de sus identidades y argumentos, en una clara acción colectiva simbólica por autorepresentarse desde sus culturas y oralidades. El pueblo mapuche en Gulumapu no ha sido la excepción. El presente artículo muestra los formatos y los contenidos temáticos que los radialistas mapuche han utilizado para desafiar, en el plano simbólico, las narraciones dominantes que difunden los medios de comunicación monopolizados del Chile contemporáneo.

\begin{abstract}
Latin American indigenous peoples have been not only marginalized and excluded, but also folklorized by social representation and omitted or distorted by mass media. Radio broadcasting, however, has been a powerful tool with which native peoples have disseminated their own identities and arguments, in a clear symbolic collective actions of self-representation that reflect their cultures and oralities. The Mapuche people of Gulumapu has been no exception. This article presents the issues and formats that Mapuche broadcasters have used to challenge the dominant narratives in Chilean mass media.
\end{abstract}
Palabras Radiodifusión, Pueblo Mapuche, Acción Colectiva Simbólica, Autorepresentación Sociocultural y clave Política, Análisis contenido formatos y temas.

Key Radio broadcasting, Mapuche people, Symbolic Collective Action, sociocultural and political selfwords representation, content analysis of issues and formats 


\section{Para conocer la Radiodifusión Mapuche en Gulumapu (Chile)}

La radiodifusión, el "medio invisible" (Lewis y Booth, 1989), ha sido la herramienta comunicacional por antonomasia de los Movimientos Sociales en el mundo, desde su aparición a principios del Siglo XX. Desde los Movimientos Obreros en la Europa de entre guerras a las radios comunitarias y educativas en Latinoamérica de los años 60's, pasando por la radiofonía guerrillera y contra informativa de los 80 's hasta llevar a la radio ciudadana de la actualidad. En todas estas expresiones las ondas radiales han ofrecido la posibilidad de visibilizar y hacer audible las voces, idiomas, culturas, ideas y demandas de cientos de grupos sociales excluidos y subalternizados por los poderes dominantes (Hale, 1979; Collin, 1983; López Vigil, 1991; León, Burch y Tamayo, 2005; Mata, 2009).

Aún iniciado el siglo XXI, con la preponderancia ascendente que han adquirido los medios de comunicación digitales, la radiodifusión análoga sigue siendo una herramienta central para los pueblos indígenas que aprovechan sus destrezas orales y lingüísticas en el uso del micrófono. De tal forma logran sortear las brechas digitales de nuestro continente, sin dejar de complementarse, cuando el acceso y conexión lo permiten, con las posibilidades de reciprocidad informativa que ofrecen páginas webs y blogs de otros comunicadores indígenas de los cientos de pueblos originarios del Abya Yala1, que incluso les permiten alojar sus podcasts y ampliar la difusión de sus mensajes.

En las siguientes páginas conoceremos los formatos y contenidos temáticos con los cuales los radialistas mapuche de Gulumapu (occidente del Wallmapu2), pugnan por autorepresentarse sociocultural y políticamente, como parte de una estrategia comunicacional mapuche que se inscribe en acciones colectivas de carácter simbólico.

Para entender tal fenómeno, primero revisaremos los elementos centrales de la acción colectiva simbólica y luego dibujaremos una breve contextualización sobre las representaciones sociales dominantes que intenta contrarrestar la estrategia comunicacional mapuche. Posteriormente, sobre la base del análisis de contenido cuantitativo y cualitativo de tres programas urbanos y una emisora rural, profundizaremos en los formatos y temas con los cuales la radiodifusión mapuche se suma a los desafíos

1 Voz kuna (Panamá) que significa "tierra en plena madurez", con la cual el movimiento indigena continental denomina a Latinoamérica.

2 Wallmapu es la totalidad del territorio histórico mapuche, que se extendía desde las costas del pacífico a las costas del atlántico, en lo que hoy se ubican regiones chilenas (Gulumapu) y argentinas (Puelmapu). 
por autorepresentarse y validarse. Por último, cerraremos este documento con algunas reflexiones finales en torno a los sentidos estratégicos que nos mostraría la radiofonía mapuche en Gulumapu.

\section{Acción colectiva simbólica: una lectura conceptual a la radiodifusión mapuche}

Cuando en 1980 se multiplicaron los Nuevos Movimientos Sociales (NMS), enfatizando demandas centradas en la cultura y la identidad colectiva, las preguntas clásicas de la sociología de la acción colectiva quedaron estrechas para explicar los elementos supuestamente novedosos de los movimientos estudiantiles, gays, feministas y medioambientales, ya que se centraban únicamente en aspectos concretos y mensurables del actuar de los movimientos sociales (Estructura de Oportunidades Políticas -EOP) y constricciones: cuándo se movilizan los actores colectivos y, el enfoque de la Movilización de Recursos (MR) y de los Repertorios de Protesta: cómo actúan los MS.

Sin embargo, los contenidos simbólicos por los cuales actúan los grupos subalternos organizados no habían sido mayormente considerados, descuidando la pregunta del por qué los actores colectivos se movilizan cuando lo hacen. Hacerse cargo de esta última pregunta implica cuestiones que se inscriben en el desafío simbólico de los movimientos contemporáneos (Melucci, 2002) o la dimensión simbólica de la acción colectiva (De la Porta y Diani, 2006).

Es decir, los actores colectivos luchan sobre todo por proyectos culturales y simbólicos, construyendo disputas por la producción cultural del sistema (Melucci, 2002, p. 70-71). Los actores movilizados buscan, a través de sus tácticas, la alteración de los significados culturales (Da Gloria, 2004, p. 259) que los descalifican y distorsionan en sus postulados. Por tal razón los movimientos sociales, antes que nada, crean marcos de interpretación sobre su situación y desarrollan vocabularios de motivos para construir sus argumentos y poder disputar las narraciones dominantes que, a su vez, justifican su papel subalternizado (Hunt, Benford y Snow, 1994; Sábada, 2001; Chihu 2006).

Tales operaciones surgen gracias a la (re)construcción de sus propios elementos culturales y sus identidades colectivas, los cuales les brindan herramientas, sustentando sus movilizaciones y demandas para lograr desafiar las representaciones sociales hegemónicas (Johston y Klanderman, 1995; Hart, 1996; Polleta, 1997). 
Junto a tales elementos, existe un tercer ingrediente en la dimensión simbólica de la acción colectiva, al parecer menos considerada en la literatura de MS, pero fundamental para los pueblos indígenas: la memoria colectiva. Catalogada como el "combustible de la identidad" (Giménez, 2009), la memoria colectiva funge como un pasado constituyente de identidades colectivas, como herramienta puesta al servicio de las operaciones de legitimación de los subalternos y, por tanto, como recurso a reivindicar frente a los olvidos de las narraciones historiográficas hegemónicas que validan a los actores sociales dominantes en su posición privilegiada.

En tal plano de la acción colectiva simbólica, la cultura, la identidad y la memoria colectiva de los actores subalternos son elementos primordiales, ya que actúan como catalizadores de un nosotros compartido y como recursos en sí mismos a defender en la interacción social por el reconocimiento válido.

Como agrega Melucci "muchos conflictos contemporáneos son expresiones de categorías sociales excluidas que reclaman acceso a las formas de representación social” (2002, p. 109). Esas formas de representación y validación social están mediadas por los medios de comunicación masivos. De hecho, diversos autores plantean cómo estos han alcanzado una importancia capital en la creación y difusión de marcos interpretativos de realidad (Zald, 1999), que ayudan a ordenar la agenda de la esfera pública (Reiter, 2002) o que, incluso, organizan los sistemas de valores y creencias sociales (Locher y Boyer, 1998).

Dada la importancia de los medios de comunicación masivos en la Sociedad de la Información y Comunicación (SIC) contemporánea, estos se han transformado en dispositivos y campos de disputa para la (re)creación y difusión de los recursos simbólicos que intentan validar, tanto los encuadres de los actores hegemónicos como los enmarcados de los actores subalternos.

No obstante, los actores colectivos llegan a este aspecto de la disputa simbólica en desigualdad de condiciones. Chihu y López (2001), citando a Gamson (1992), refieren que los actores dominantes realizan activos procesos de contraenmarcamiento, los cuales tienen por propósito "minar la legitimación del significado que el movimiento social atribuye a sus propios diagnósticos y a sus estrategias y propuestas de solución" (2001, p. 449). 
Precisamente, este es el desafío simbólico que los comunicadores indígenas asumen y desarrollan, a través de sus emisiones radiofónicas o a través de sus herramientas de difusión comunicacional. Elaborar mensajes para difundirlos equivale al uso y la demanda por el reconocimiento de sus cultura(s), identidad(es) y memoria(s) colectiva(s) ancestrales, que al mismo tiempo les brindan las herramientas para enfrentar y denostar las añejas y nuevas operaciones simbólicas de deslegitimación social, del mismo modo que les permiten enfrentar las clásicas operaciones de contraenmarcado hegemónico (Gamson, 1992), tergiversación o subrepresentación de los medios de comunicación masivos (Gitlin, 2005), el racismo discursivo (Van Dijk, 1997 y 2009, Leung, 2005) o incluso la violencia simbólica y estructural que validan los medios (Penalta y de la Parra, 2008).

No obstante, el acceso a los medios de comunicación masivos, cada vez más monopolizados en la región y en nuestro país, es escaso y para muchos sujetos sociales está clausurado. Por tanto, para acceder al "poder de nombrar la realidad" (Melucci, 2002, p.17), los actores colectivos autogestionan medios de comunicación alternativos, buscando construir sus propias oportunidades comunicacionales. Todo, con el fin último, parafraseando a Mata (2009), de irrumpir en la esfera pública, hacerse visible para demandar los derechos negados o exigir nuevos derechos, además de nombrar la realidad desde su propio punto de vista. Tal sería el motivo primordial de la acción colectiva comunicacional indígena en Latinoamérica y Mapuche en Gulumapu.

\section{Representaciones dominantes chilenas y la respuesta comunicacional mapuche}

La ocupación militar chilena de la Araucanía (llamada eufemísticamente pacificación por la historiografía nacional), terminó con la soberanía territorial del territorio mapuche al sur del río Bío Bío, ganada durante la Guerra de Arauco frente a la Corona Española. Tal operación de despojo armado estuvo precedida por una operación narratológica justificatoria que se difundió a través de la prensa de ocupación (Pinto, 2000 y Cisternas, 2000), donde las páginas de El Ferrocarril de Santiago (1855-1912) y El Mercurio de Valparaíso (1827- actualidad) resultaron claves.

Al admirado "Araucano jamás vencido" (Ercilla, 1997), modelo a seguir por los libertadores de la guerra de independencia sudamericana, había que denostarlo simbólicamente antes de poder colonizarlo por la vía de la violencia armada. El pueblo mapuche transitó de la inclusión a la exclusión del proyecto estado nacional chileno (Pinto, 2000), que permitió 
construir la hegemonía monoétnica chilena (Roitman, 1996), la consolidación territorial y consecución de excedente económico (Zavaleta, 1987), además del triunfo del Estado unitario. Todo, a través de la imposición del colonialismo interno (González Casanova, 1969 y Marimán, 2004) y subalternización al pueblo mapuche, sobre la base de su etnicización (Giménez, 2009), al aplicarles por la fuerza la desterritorialización y la desestructuración sociocultural ${ }^{3}$. Así se creó un conflicto étnico que se arrastra hasta nuestros días 4 .

En la historia de relaciones interculturales asimétricas entre el Estado nacional chileno y el pueblo nación mapuche, a partir de 1990 parece repetirse una dinámica similar a la precedente, ahora desde la cuasi inexistencia mapuche en los imaginarios sociales chilenos a una profusa cobertura mediática, pero delincuencial. A principios de la década de 1990 el pueblo mapuche organizado aprovechaba las oportunidades políticas que ofrecía la transición a la democracia chilena, exigiendo el compromiso de reconocimiento de derechos específicos a la Concertación, alianza política que gobernó Chile (1990 y 2010).

En un primer periodo (1990-1997) los gobiernos concertacionistas reconocieron a las poblaciones indígenas a través de la promulgación de la Ley Indígena (1993) y la creación de la Corporación Nacional de Desarrollo Indígena (CONADI), aunque la sociedad mayoritaria siguió desconociendo a los mapuche a través de los medios de comunicación masivos, pues los editores ignoraban y subvaloraban los temas indígenas (Baltra, 2000). Durante esos años, las estrategias de acción colectiva seguidas, en líneas generales, por las principales organizaciones mapuche de la época fueron de: a) ciudadanización, hacer cumplir los derechos alcanzados y seguir demandando la ratificación del Convenio 169 de la OIT (alcanzado en 2008), además del reconocimiento constitucional jamás logrado, b) argumentación, recogiendo la historia propia, un grupo de investigadores mapuche depuraron aquel Nuevo discurso mapuche de los 80's (Caniuqueo, 2006) para transformarlo en la discursividad política mapuche actual, inaugurando su difusión a través del ciberactivismo y de la radiodifusión alternativa autogestionada, y c) tomas simbólicas, ocupaciones de predios para recordar la deuda territorial del Estado chileno con el pueblo mapuche y sumándose a las acciones del movimiento indígena continental por los 500 años del genocidio del Abya Yala.

3 Con la Ocupación de la Araucanía el estado chileno se anexó 5 millones de hectáreas, entregadas a colonos nacionales y europeos, mientras que el pueblo mapuche fue confinado a vivir en reducciones, en el 5\% de su territorio ancestral (Bengoa, 1985; Mella, 2007).

4 Sobre las distintas expresiones que las representaciones sociales dominante que sobre el Pueblo Mapuche se difundieron durante gran parte del siglo XX revisar: Foerster y Montecinos, 1988; Cisternas, 2000; Subercaseaux, 1999; Martínez et al, 2003; Larraín, 2001 y Muzzopappa, 2003. 
Un segundo periodo (1997-2010) estuvo signado por un doble accionar desde las hegemonías políticas y económicas. Por un lado, los gobiernos de la Concertación crearon: mesas de diálogo comunal (1999), entregaron recursos financieros para proyectos productivos en las comunidades (BID-Orígenes, 2001), convocaron a una Comisión de Verdad Histórica y Nuevo Trato (2003) y se comprometieron con Re-conocer: Pacto Social por la Multiculturalidad (2008), entre otras acciones y programas gubernamentales. Por otro lado, el año 1997 marcó la fecha en que la voluntad política de los gobiernos concertacionistas consagraron la defensa de los intereses económicos neoliberales por sobre los derechos indígenas alcanzados y se sumaron a la construcción social del "mapuche terrorista", surgido al alero de las empresas forestales, como un justificativo simbólico para la criminalización de la protesta social mapuche (Aylwin, 2007; Seguel, 2007; Mella, 2007; Le Bonniec, 2008).

Tal estigmatización delincuencial ostenta hasta el día de hoy el mismo patrón de reproducción, surgido en Lumaco en 1997, a raíz del primer incendio de maquinaria forestal ocasionado por comuneros mapuche frente a la extrema pobreza en esa comuna de la Araucanía (Leiva y Villagrán, 1998). A saber: a) los directivos de las empresas forestales rumorean la infiltración subversiva, invocando la Ley de Seguridad Interior del Estado (1997) y luego la Ley Antiterrorista (2002); b) las autoridades de gobierno regional y nacional adhieren a tales denuncias; c) los tribunales de justicia acogen y procesan a comuneros mapuche en juicios con testigos protegidos y sin rostro por Ley Antiterrorista, irrespetando el debido proceso $y$, finalmente, d) los medios de comunicación masivos monopolizados difunden y refuerzan la representación social del "mapuche terrorista".

Ante tal novedosa representación social delincuencial del mapuche, generalmente se les ha clausurado la posibilidad de desmentirse y explicarse en sus argumentos y razones de protesta (Díaz y Olavarría, 2000; Otazo, 2003; Álvarez y Pineda, 2006; Sandoval, 2007). Los propios comunicadores mapuche han denunciado montajes comunicacionales, con el fin de denostar su lucha y defender los intereses económicos inmiscuidos, repitiéndose a nuestro juicio una operación de desprestigio social similar a la efectuada a finales del siglo XIX por la llamada prensa de ocupación (Villagrán, 2014, p. 163-169).

Tal papel de los medios de comunicación masivos se juega en tiempos de una extrema monopolización, que clausura la difusión del pluralismo político y la diversidad sociocultural, más por el monopolio ideológico de los empresarios chilenos, educados 
en una matriz económica neoliberal y en un conservadurismo valórico, que por la monopolización en sí misma (Sunkel y Geoffrey, 2003, p.110-115). Se conserva "el modelo de sociedad (neoliberal) implantado a la fuerza bajo la dictadura" (Monckeberg, 2009, p. 438), y se consagra la socialización chilena en base a una supuesta homogeneidad sociocultural "blanquista" y excluyente del otro indígena.

Frente a tal contexto contemporáneo, el movimiento mapuche ha mostrado una diversificación de sus apuestas organizativas, en un nuevo ciclo de protesta mapuche a partir de 1997 (Levil, 2006). Las estrategias seguidas son: a) disruptiva: que ha sido aprovechada por los poderes dominantes para reproducir la construcción social del "mapuche terrorista" que sirve de justificativo simbólico para llevar a cabo la criminalización de la protesta social mapuche; b) territorialista: que ha trabajado por la restitución de las identidades territoriales que brindaban una gobernabilidad extendida al pueblo mapuche antes de ser colonizado (Marimán, 2006) y c) nacionalista: expresada en la búsqueda de un debate y un pacto político que posibilite la creación de un estatuto de autonomía participativo y democrático (Levil2011).

Sumado a este escenario de organización mapuche en Gulumapu, se ha aquilatado en las últimas dos décadas (1990-2010) un cierto lenguaje común, expresado en la llamada "discursividad política mapuche actual" por los propios investigadores mapuche (Antileo, 2010; Levil,2011). Tal lenguaje se traduce sintéticamente en que la condición de colonialidad de la nación o país mapuche ha provocado la desestructuración sociocultural, política y económica de este pueblo, misma que explica, tanto la pauperización del Wallmapu (territorio histórico) como la diáspora mapuche que vive en condiciones de exclusión, discriminación y alta urbanidad (79\% según censo 1992) 5 .

De la condensación de esta "discursividad política mapuche" de los años recientes, creemos que surge el fenómeno de la emergencia comunicacional mapuche, estrategia que se entrelaza con el resto de acciones colectivas mapuche y que pugna por autogestionar sus propios medios de comunicación alternativos que les permitan auto-representarse y legitimarse sociocultural y políticamente, desafiando en el plano simbólico las narraciones dominantes de contraenmarcado que los aquejan, así como también la monopolización de los medios masivos.

5 Aunque tal lenguaje está plasmado en una serie de documentos con distintos énfasis, nos parece que el escrito más claro para entender los argumentos de tal discursividad se encuentra en el EPílOGO DEL LIBRO i... ESCUCHA, WINKA...! (MARIMÁN ET AL, 2006). 
Creemos que tal estrategia recoge, además, la experiencia de los primeros escritos mapuche de principios del siglo XX (Cuminao, 2007), de los primeros periódicos mapuche (La Voz de Arauco, Temuco, 1938 y La Voz Araucana, Santiago, 1943) y de la decena de boletines mapuche de los 80's, para multiplicar, a partir de 1990, la discursividad política mapuche actual en el ciberespacio y en la radiodifusión. Ambas herramientas se complementan en la difusión de sus contenidos, al recoger la radiofonía mapuche informaciones digitales, mientras que las plataformas de información virtual ponen a disposición de las emisiones análogas las posibilidades de archivar en podcasts sus programas para su reproducción en diferido.

\section{Las formas y contenidos temáticos de los desafíos radiofónicos mapuche}

Sobre tal nutrido contexto de inclusiones y exclusiones hegemónicas, pero sobre todo sobre la base de la construcción de un mensaje mapuche propio, que intenta argumentar sus luchas y explicar sus argumentos, es que interrogamos la radiodifusión mapuche en Gulumapu (Chile), entendida como una herramienta trascendental de la estrategia comunicacional mapuche contemporánea, que lleva a cabo desafíos simbólicos de autorepresentación sociocultural y de legitimación política.

Entonces, ¿qué formatos ocupan los radialistas mapuche? ¿Sobre qué temas preferentemente conversan en sus emisiones radiofónicas? ¿Con qué contenidos y sentidos desafían la construcción social imperante del "mapuche terrorista"? Tales preguntas las contestamos sobre la base del análisis de contenido, cuantitativo y cualitativo, al cual sometimos las emisiones radiofónicas mapuche a las cuales tuvimos acceso (tres programas y una emisora mapuche), entre los meses de noviembre de 2009 y febrero de $2010^{6}$.

En un primer nivel de interpretación de los contenidos manifiestos de las emisiones, empleamos el análisis de contenido en su versión cuantitativa, con el objeto de desentrañar aspectos formales específicos de cada experiencia y poder cuantificar porcentualmente el tiempo que cada programa y/o radioemisora destina a la música y a los contenidos temáticos, brindándonos una primera valoración sobre la importancia de determinados asuntos de conversación. Los contenidos temáticos fueron divididos en dos grupos: I) Socioculturales e Históricos mapuche (observar cómo las emisiones radiofónicas (re)

6 Fueron 33 horas de emisiones radiofónicas, entre noviembre de 2009 y marzo de 2010, que vaciamos en 247 fichas, siguiendo la técnica de análisis de contenido cualitativo y cuantitativo (Ruíz, 1996; Piñuel, 2002). 
construyen y (re)crean elementos relacionados a su identidad, cultura e historia, en orden a entender una posible autorepresentación sociocultural) y II) Temas "Conflicto Mapuche" (para analizar cómo se sitúan frente al marco interpretativo dominante con el cual han sido representados en la esfera pública chilena contemporánea).

En un segundo y posterior nivel de exploración de los contenidos latentes e implícitos de las emisiones radiofónicas, recurrimos al análisis de contenido cualitativo, entendido como la realización de una entrevista a un texto, en este caso, textos orales enunciados por los radialistas mapuche o por sus entrevistados. Así, rescatamos fragmentos discursivos significativos (citas textuales) de las emisiones radiofónicas, los cuales relacionamos con los marcos de interpretación que subyacen en relación a la construcción de: a) sus marcos de diagnósticos sobre su situación ("conflicto mapuche" actual) y b) atribuciones de identidad propia y de ciertos actores sociales chilenos, principalmente. Tal tratamiento nos facilitó visibilizar las connotaciones de significados que emiten las radioemisiones mapuche, permitiéndonos ahondar cualitativa e interpretativamente en el análisis de los contenidos implícitos (Villagrán, 2014, p.61 - 68). Revisemos primero, sucintamente, las formas y contenidos explícitos de las radioemisiones.

\subsection{Amuleaiñ: Un Foro Radiofónico Mapuche}

Cortina Presentación: “Amuleaiñ kom pu lagmien, adelante hermano! Amuleaiñ es un programa producido por la Comisión Jurídica Indígena Urbana Warranca. Este programa tendrá una preocupación especial por el marco jurídico nacional e internacional de los derechos de los pueblos originarios, por la participación, la formación y la capacitación y, por cierto, la promoción de nuestros derechos como pueblo. Bienvenidos! Amuleaiñ! “

Así inicia cada sábado el programa Amuleaiñ (adelante hermano en mapudungun), transmitido por las ondas de Radio Nuevo Mundo de Santiago (930 AM), desde febrero de 2004 hasta la actualidad. Esta emisora es de propiedad del Partido Comunista de Chile (PCC), por lo que su línea editorial coincide con la difusión del pensamiento crítico y de los movimientos sociales chilenos.

Amuleaiñ surgió por la inquietud de contar con un instrumento de comunicación propio por parte de un colectivo de organizaciones mapuche urbanas que, en 2001, empezaron a formar la Comisión Jurídica Indígena Urbana Warranca. Y, aunque tal instancia organizativa descontinuó su trabajo, el equipo de radialistas mapuche de Amuleaiñ ha mantenido el espacio radiofónico para enfrentar "este gran monstruo que es la prensa de la sociedad mayoritaria" (Conductor 1, marzo 2010). 
El análisis de las emisiones muestra que Amuleaiñ privilegia los contenidos temáticos (91.6\% tiempo total emisiones) por sobre la programación musical (8\%). Y, cuando éstas son utilizadas, se acude a la música instrumental mapuche o cantada en mapudungun. Esto se debe a que la principal característica formal de Amuleaiñ es que sus emisiones se han instituido en lo que llamaremos "foros temáticos radiofónicos". Ya sea que los invitados sean mapuche expertos en algún área del mapuche kimún (conocimiento) y se establezca un nütram (conversación) en formato de entrevista radiofónica, o que los conductores ocupen el espacio para hacer un intercambio de opinión y análisis sobre algún asunto en específico.

¿Sobre qué temas se conversa en Amuleaiñ? El tratamiento de Temas Socioculturales e Históricos es relativamente bajo en este espacio (36.5\% del tiempo total de contenidos) y, generalmente, aborda asuntos tales como: el rescate histórico, el rescate idiomático, la historia como orígenes del conflicto entre el pueblo mapuche y el Estado nacional chileno, además de explicar y demandar derechos indígenas (Convenio 169 de la OIT, prioritariamente). Mientras tanto, durante un $55 \%$ del tiempo de contenidos se refieren a algún asunto relacionado al llamado "conflicto mapuche", entre ellos: el despojo territorial, la vulneración de Derechos Humanos e indígenas, además de la represión y criminalización, principalmente. Además, refutan directamente el apelativo de "mapuche terrorista" impuesto en los últimos años.

\subsection{Newen Mapu: Informativo sobre la Sociedad Mapuche Urbana de Concepción}

Cortina Presentación: “La Asociación Mapuche Newen Mapu de Concepción presenta su programa ¡Fuerza de la Tierra! La voz del mapuche de ayer, de hoy y de siempre.”

Así comenzaba el programa Newen Mapu (fuerza de la tierra en mapudungun), que se transmitió entre 2006 y 2012 todos los martes, a través de Radio Voz de la Mujer de Concepción (98.5 FM). Esta emisora es una radio comunitaria que transmite desde 1998 al alero de la organización social Casa de la Mujer de Concepción, por lo que es considerada la primera radio comunitaria de la Región del Bíobío.

Newen Mapu surgió como una idea del conductor, quien posee experiencia previa en radiodifusión y es miembro del directorio de la Asociación Newen Mapu de Concepción. El propósito de este espacio fue ser "la voz de la organización (...) Para dar a conocer que los mapuche están presentes en la ciudad, que se están organizando, para recuperar principalmente su cultura, sus tradiciones". (Fuente: Conductor, febrero 2010) 
Newen Mapu era un espacio donde el conductor privilegiaba el tiempo de emisión para entregar contenidos temáticos (71.8\%), frente a la programación musical (28\%). En él se leían informaciones sobre la sociedad mapuche y se difundían las actividades de las organizaciones mapuche urbanas de la ciudad y provincia de Concepción. De esta forma, el $60 \%$ del tiempo de contenidos se dedicaba a difundir temas socioculturales e históricos sobre la sociedad mapuche (noticias misceláneas, la realización e importancia del guillatún, explicación del Convenio 169 de la OIT, el rescate sociocultural y la demanda de vivienda de los mapuche penquistas).

Un escaso $11 \%$ del tiempo de contenido se utilizaba para conversar sobre el denominado "Conflicto Mapuche" y sus consecuencias (las secuelas de los niños en los allanamientos, el estado de las investigaciones de los weichafes (guerreros) asesinados, la discriminación, la exclusión de la nación chilena y su falta de entendimiento de las demandas mapuche, así como la vulneración de derechos en torno a la libertad de expresión y el papel que cumplen los comunicadores mapuche).

\subsection{Wixage Anai: Un Coro de Voces Mapuche Viviendo en la Diáspora Santiaguina}

Cortina Presentación: “El Centro de Comunicaciones Mapuche Jufken Mapu presenta: Wixage Anai! Wixage Anai (fragmento en mapudungun). Wixage Anai, un programa mapuche para reencontrarnos con nuestra historia y nuestra forma de ver el mundo. Un programa para fomentar los lazos de unión de nuestra gente y fortalecernos como pueblo nación mapuche."

Con esta imagen sonora inicia cada emisión del programa radiofónico Wixage Anai (levántate o despierta en mapudungun). Este espacio empezó a transmitirse en 1993 a través de Radio Nacional (ahora extinta), llegando a constituirse en un referente, debido a su estilo y permanencia en el dial. Esta experiencia surgió debido a una necesidad de rescate sociocultural e idiomático mapuche propio de la urbanidad: "lo primordial en nuestro programa es que el idioma se mantenga, que el idioma mapuche no se pierda, porque está bastante débil. En muchas comunidades no se habla el mapudungun y acá en Santiago es mucho más complicado" (Conductora, enero 2010).

Luego de pasar por Radio Yungay (1996-2000) llegaron a Radio Tierra de la Corporación La Mora (ONG feminista), hasta el cierre de esta emisora (2013). Actualmente el programa sigue difundiendo sus emisiones a través de podcasts, los cuales se cuelgan en páginas webs mapuche o a través de listas de mails. 
En términos formales Wixage Anai se caracteriza por ser un coro de voces mapuche al aire, en una especie de plataforma comunicacional puesta al servicio de la difusión de los mensajes de la sociedad mapuche en su conjunto. Mientras los contenidos temáticos ocupan un $82.7 \%$ del tiempo total de emisiones, la programación musical alcanza el $17 \%$ del tiempo total, enfatizando la emisión de sonidos ancestrales. Es decir emiten sonidos de instrumentos autóctonos y cantos en mapudungun, en sus expresiones de ülkantún (historia cantada), ayekán (música de diversión) y purrún (música de baile religioso). Tal apuesta de rescate de sonidos y fomento idiomático activo se acompaña con emisiones bilingües (mapudungun- español) en un $41 \%$ del tiempo de contenido analizado.

Wixage Anai otorga más tiempo a los Temas Socioculturales e Históricos (55\% del tiempo de contenidos) relacionados con el rescate social y cultural en sí, el rescate religioso e idiomático, además de referirse al papel de los medios de comunicación mapuche en abierta contraposición a los medios masivos. En tanto, los temas relacionado al denominado "conflicto mapuche" ocupan sólo un $27.5 \%$ del tiempo de contenidos, donde se impugnan la criminalización, represión y asesinato de weichafes, relacionado directamente con la denuncia de la vulneración de Derechos Humanos e indígenas.

\title{
Radio Werkén Kurvf: Agenda Noticiosa desde una Perspectiva Mapuche Lafkenche ${ }^{7}$
}

\begin{abstract}
Cuña de continuidad: "El cariño que se tiene a la made naturaleza, lamentablemente, se ha olvidado. Todo eso por la intervención de los winkas. Cada vez nos imponen grandes proyectos, arrasando con todo lo que existe en nuestra tierra. Es más, ya no nos quedan lugares sagrados. Sin embargo, yo como guillatufe me preocupo por lo que está pasando. Mi misión es informarles y orientar a mi gente del lof. Es una reflexión de su Radio Werkén Kvrvf, 98.3"
\end{abstract}

Cuando alguien en una comunidad ancestral mapuche de la novena región de la Araucanía, en Gulumapu (Chile), realizaba hasta el año 2011 la acción de cambiar el dial de su radiotransistor, podía encontrarse con las emisiones de Radio Werkén Kvrvf (mensajero del viento en mapudungun) en el dial 98.3 de la banda FM. Esta radioemisora mapuche Lafkenche transmitió desde el 11 de septiembre de 2004, a más de 100 comunidades mapuche ubicadas en una zona rural costera de la Región de la Araucanía, además de alcanzar varias ciudades cercanas ${ }^{8}$.

\footnotetext{
7 La identidad mapuche Lafkenche es la identidad territorial de aquellos mapuche que viven del lafkenmapu o territorio del mar.

8 Cuenta con una concesión de radioemisora comercial, que le faculta para transmitir, durante 25 años, con 100 watt de potencia y un alcance de 40 kilómetros a la redonda, así como también poder captar avisos publicitarios. Por problemas de salud dejaron de transmitir.
} 
Radio Werkén Kurvf se creó al alero de una amplia movilización y organización social mapuche Lafkenche, que pretendió gestionar, con principios de autonomía los recursos financieros que el gobierno chileno pretendía invertir en su territorio, a través del Programa Bid-Orígenes. A raíz de ello surgió un Consejo de Werkenes (1999), quienes propusieron crear un medio de comunicación propio, que les permitiera una mejor comunicación interna, además de rescatar y fortalecer la cultura mapuche de las comunidades inmiscuidas, enclavadas en un entorno de discriminación winka.

"Hay gente que nos escucha porque simpatiza con nosotros y con nuestra causa y otros que derechamente no nos van a escuchar aunque nosotros hagamos un programa destinado a ellos, porque son simplemente antimapuche (...) pa' ellos es la radio de los indios que no saben hablar, porque muchos peñis, que ahora lamentablemente no están, por hablar mapudungun, había muchas palabras en castellano que no podían pronunciar correctamente. Entonces pa' ellos era impensable que saliera en la radio: los indios no saben ni hablar y se creen locutores." (Director, noviembre 2009).

Radio Werkén Kurvf programaba música heterogénea (32\% tiempo total de emisiones) con el fin de captar audiencia que les permitía traspasar sus mensajes sobre lo que ocurre en las comunidades mapuche movilizadas y sus razones históricas de lucha. Así, del tiempo de contenido (67\% del tiempo total) se utiliza para difundir temas socioculturales e históricos ( $41 \%$ del tiempo de contenido), donde se difunden: comentarios críticos y con pertinencia local y mapuche sobre el acontecer noticioso nacinal e internacional, defensa del medioambiente e historia como orígenes del conflicto.

Por otro lado, el 22\% del tiempo de contenidos se utiliza para conver sar sobre asuntos relacionado al llamado "conflicto mapuche" (criminalización y represión de la protesta social mapuche, vulneración de los Derechos Humanos e indígenas). No obstante, una cuestión importante en estas emisiones y ausente en el resto, fue la denuncia de la exclusión política que sufre el pueblo mapuche, expresado en la falta de representantes en el Congreso Nacional chileno. 


\section{Reflexiones finales}

¿Cuáles son los principales sentidos estratégicos implícitos que emergen de las radioemisiones mapuche analizadas?

En esta fotografía sintética, hemos pretendido resumir un primer nivel de análisis de los contenidos formales y temáticos de las emisiones radiofónicas examinadas, destacando que cada experiencia de radiodifusión mapuche en Gulumapu posee su sello distintivo, dando cuenta de la diversidad de la estrategia comunicacional de los radialistas mapuche. Al poner los casos en paralelo comenzamos a advertir las primeras interpretaciones posibles sobre los sentidos estratégicos de tales emisiones.

Por un lado, y contrario a uno de nuestros supuestos iniciales, el tiempo dedicado a responder directamente el agravio simbólico de la estigmatización terrorista, como marco de interpretación construido socialmente por las hegemonías chilenas contemporáneas, es bastante minoritario. Lo cual no significa que no muestren su indignación frente a situaciones que agrupamos bajo la temática del llamado "conflicto mapuche", tales como la represión, la criminalización y la vulneración de Derechos Humanos e indígenas y que cobran su máxima expresión de pesar en la rememoración del asesinato impune de los jóvenes weichafes a manos de integrantes de la policía uniformada chilena (Carabineros).

Por el contrario, los propósitos declarados, el tiempo mayoritario utilizado y los temas tratados están dirigidos, principalmente, a construir un marco de interpretación propio para explicar y difundir quiénes son como pueblo nación mapuche, en términos socioculturales, idiomáticos, cosmogónicos e históricos, echando mano de sus propios recursos simbólicos, vale decir, se autorrepresentan a partir de su cultura, identidad y memoria colectiva mapuche. No se quedan en lo coyuntural del llamado "conflicto mapuche" construido como tal por los poderes dominantes chilenos.

Un segundo nivel de análisis, respecto a profundizar en los significados y sentidos estratégicos, nos sugieren, en primer lugar, que los marcos de interpretación que los comunicadores radiofónicos mapuche vienen desarrollando en sus emisiones se centran en connotar la importancia de entender que el llamado "conflicto" no empezó en 1997 sino que en 1881, cuando el ejército chileno perpetró la ocupación militar de la Araucanía, suspendiendo la soberanía mapuche y relegándolos a una situación de colonialidad, con todas las consecuencias posteriores. Acontecimiento que se vuelve el conflicto fundacional 
entre el pueblo mapuche y la sociedad chilena, pero sobre todo se vuelve el argumento central y primogéneo de su situación y demandas actuales como pueblo. Sobre la base de tal diagnóstico se autorepresentan como un pueblo y/o nación con su propia historia, cultura, identidad e idioma.

En segundo lugar, identifican a sus adversarios, donde el primer y principal oponente es el Estado nación chileno, aunque también los gobiernos de turno que aplican las políticas de represión a la protesta, así como también los tribunales de justicia y las policías. Mientras que, por el contrario, reconocen en la sociedad civil chilena no dominante una cercanía solidaria, en especial en los últimos años. En menor medida, también identifican al modelo económico neoliberal como un adversario poderoso y que se ha transformado en un antagonista protegido por el resto de actores hegemónicos chilenos.

Asimismo, otro actor social winka importante, ya que se vuelve su alter ego, lo constituye los medios de comunicación masivos chilenos, que crean cercos y montajes comunicacionales, además de difundir la estigmatización terrorista. $Y$ es frente a ellos que los radialistas mapuche identifican la importancia de su trabajo como comunicadores, ya que disputan un desafío simbólico por cambiar los códigos culturales discriminantes que la sociedad dominante les atribuye.

Por lo tanto, a la luz del análisis de contenido (cuantitativo y cualitativo) de las emisiones radiofónicas examinadas, concluíamos que, efectivamente, la radiodifusión mapuche en Gulumapu es un ejercicio de acción colectiva comunicacional para la autorepresentación sociocultural de su pueblo y la legitimación de sus demandas, erigiendo una disputa de significados en el plano simbólico. Disputa por nombrar(se) y validar(se) que desmiente de manera propositiva, sobre la base de su identidad cultural y su memoria histórica, el calificativo peyorativo contemporáneo del "mapuche terrorista”, enmarcado hegemónico deslegitimante.

Puesto que explican desde su propia versión quiénes son ellos, qué es lo que demandan y por qué lo demandan, manifestamos que llevan a cabo una lucha por explicarse y validarse, (re)construyendo sus propios argumentos, imagen y audiobilidad, fuertemente alimentados por su propia historia y cultura, a pesar del infranqueable escenario mediático y hegemónico chileno, que defiende los intereses económicos empresariales neoliberales y la idea de una sociedad monoétnica. 
En este sentido, la expresión radiofónica mapuche, enmarcada en una estrategia comunicacional amplia y diversa, puede por fin establecer diálogos interculturales con la sociedad civil chilena, una estrategia perviviente a lo largo de décadas en las manifestaciones de acción colectiva mapuche, pero que también ha sido ensombrecida en la batalla hegemónica del desprestigio impuesto a este pueblo indígena de Gulumapu.

\section{Referencias}

Antileo, E. (2010) urbano indígena. Diálogo y Reflexión en Santiago Warria. Working Series 31. Ñuke Mapufôrlaget. Disponible en la web: www.mapuche.info/wps_pdf/antileo20100919 Revisado junio 2011.

Álvarez, L. y Pineda, L. (2006) Tratamiento informativo de la etnia mapuche en la prensa escrita chilena: los casos de El Mercurio y El Sur. (Seminario Licenciatura Comunicación Social, Universidad de Concepción, Chile).

Aylwin, J. (2007) La política del 'Nuevo Trato': antecedentes, alcances y limitaciones. En N. Yañez y J. Aylwin (Ed), El Gobierno de Lagos, los pueblos indígenas y el 'nuevo trato'. Las paradojas de la democracia chilena. Santiago, Lom Ediciones.

Baltra, L. (2000, marzo) Los medios de comunicación social y el Tema Indígena. Encuesta a editores de medios de comunicación de Santiago en 1996-97. Unidad de Comunicación y Relaciones Públicas, CONADI. Trabajo presentado en Seminario de Comunicaciones y Cultura Indígena para el nuevo Milenio, Programa de Magíster en Comunicación, Universidad Diego Portales, Ceneca, Conacin, Wacc, Santiago.

Barre, M. C. (1983). Ideologías Indigenistas y Movimientos indios. Ciudad de México, Siglo XXI Editores. Bello, A. (2004) Etnicidad y Ciudadanía en América Latina. La acción colectiva de los pueblos indígenas. Santiago, CEPAL.

Bengoa, J. (1985) Historia del Pueblo Mapuche Siglos XIX y XX. Santiago, Pehuén Editores.

Brett, R. (2006) Movimiento Social, Etnicidad y Democratización en Guatemala (1985-1996). Ciudad de Guatemala, F y G Editores.

Bonfil Batalla, G. (1979) Utopía y revolución: el pensamiento político de los indios en América Latina. Ciudad de México, Nueva Imagen Editores.

Caniuqueo, S. (2006) Siglo XX en Gulumapu: De la Fragmentación del Wallmapu a la Unidad Nacional Mapuche. 1880 a 1978. En P. Marimán et al j...Escucha Winka...! Cuatro ensayos de Historia Nacional Mapuche y un epílogo sobre el futuro. Santiago, Lom Ediciones.

Castells, M. (1999) La era de la información. Economía, sociedad y cultura. El poder de la Identidad. Vol II. México, Siglo Veintiuno Editores.

Cisternas, J. (2000) Lucha étnica por conquistar espacios de expresión. El caso mapuche en la prensa del Chile republicano. ¿Una guerra de Arauco medial posmoderna? (Memoria Título de Periodista, U. de Chile. Santiago, Chile). 
Chihu, A. (2006) El 'análisis de los marcos' en la sociología de los movimientos sociales. Ciudad de México, UAM Iztapalapa y Editorial Miguel Ángel Porrúa.

Collin, C. (1983) Radiopoder. La radio como instrumento de participación social y política. Ciudad de México, Folios Ediciones.

Cuminao, C. (2007) Ensayo en torno a los escritos mapuche. En Zapata, C. (Comp): Intelectuales Indígenas. Piensan América Latina. Quito, Ediciones Abya Yala.

Della Porta, D. y Diani, M. (2006) Social movements. An introduction. Blackwell plublishing.

Da Gloria, M. (2004) Teorias dos Movimentos Sociais. Paradigmas Clássicos e Contemporaneos. Sao Paulo, Ediciones Loyola.

Díaz, S. y Olavarría, V. (2000) Representación Social del Grupo Étnico Mapuche en un Medio de prensa escrito nacional. (Tesis Licenciado Comunicación Social. Universidad de la Frontera, Temuco, Chile).

Ercilla, A. (1997) La Araucana. Santiago, Editorial Ercilla.

Foerster, R. y Montecinos, S. (1988). Organizaciones, Líderes y contiendas Mapuches (1900-1970). Santiago, Ediciones del Centro de Estudios de la Mujer (CEM).

Giménez, G. (2009) Identidad y Memoria Colectiva En: Identidades Sociales México, Conaculta e Instituto Mexiquense de Cultura, México.

Gitlin, T. (2003). "The Media in the Unmaking of the New Left". En The Social Movements Reader. Cases and Concepts. USA: Cornwall, Blackwell.

González Casanova, P. (2006). Colonialismo Interno En Sociología de la Explotación. Buenos Aires, Editorial Clacso.

Gutiérrez, F (2014). We aukiñ zugu. Historia de los Medios de Comunicación mapuche. Santiago, Quimantú

Hale, J. (1979) La Radio como Arma Política. Barcelona, Ed. Gustavo Gili.

Hart, S. (1996) The Cultural Dimension of Social Movement: A Theorical Reassessment and Literature Review. En: Sociology of Religion, 57:1, 87-100.

Hunt, S; Benford, R. y Snow, D. (1994) Marcos de Acción Colectiva y Campos de Identidad en la Construcción Social de los Movimientos. En Chihu, A. Coord.: El 'análisis de los marcos' en la sociología de los movimientos sociales. Ciudad de México, UAM Iztapalapa y Editorial Miguel Ángel Porrúa.

Johnston, H. y Klandermans, B. (1995) The cultural Analisis of Social Movement. En Johnston y Klandermans eds: Social Movement and Culture (pp3-24) Mineapolis, University of Minesota Press.

Kymlicka, W. (1995). Ciudadanía Multicultural. Una teoría liberal de los derechos de las minorías. Barcelona, Paidós.

Kymlicka, W. (2007) Odiseas Multiculturales. Las Nuevas Políticas Internacionales de la Diversidad, Barcelona, Paidós.

Larraín, J. (2001) Identidad Chilena. Santiago, Lom Ediciones 
Le Bonniec, F. (2008) Crónica de un juicio antiterrorista contra los dirigentes Mapuche. Imposición y uso del derecho entre los Mapuche de Chile. En Santamaría, A; Base, B y Wittersheim, E. Eds.: Luchas indígenas, trayectoria poscoloniales. América y Pacífico. Bogotá, Ed. Universidad del Rosario.

Leiva, D. y Villagrán, C. (1998) Lumaco y Purén. Los puntos visibles de una demanda ancestral Mapuche. (Seminario Licenciatura en Comunicación Social, Universidad de Chile).

León, O.; Burch, R.; Tamayo, E. (2005) Movimientos Sociales y Comunicación. Quito, Agencia Latinoamericana de Información (ALAI).

Leung, L. (2006) Etnicidad Virtual. Raza, resistencia y Worl Wide Web. Barcelona, Gedisa editores.

Lee Van Cott, D. (2005) From Movements to Parties in Latin America. The evolution of ethnic politics. Cambridge University Press.

Levil R. (2006) Sociedad Mapuche Contemporánea. En P. Marimán, S. Caniuqueo, Melillán y R.Levil Ed i...Escucha, Winka...! Cuatro ensayos de Historia Nacional Mapuche y un epílogo sobre el futuro. Santiago, Lom Ediciones.

Levil X. (2011) Configuraciones del Movimiento Mapuche en Chile y Argentina. Procesos Políticos y Etnonacionalistas que se construyen a partir del Accionar y Reflexión de sus Representantes. (Tesis Doctorado en Ciencias Sociales, Ciesas Occidente, Guadalajara, México).

Lewis, P. y Booth, J. (1989) El medio Invisible. Radio Pública, privada, comercial y comunitaria. Barcelona, Ediciones Paidós.

Lochard, G. y Boyer, H. (1998). La Comunicación Mediática. España, Editorial Gedisa.

López Vigil, J. I. (1991). Las mil y una historias de Radio Venceremos. San Salvador, UCA Editores.

Marimán, P. (2006) Los Mapuche Antes de la Conquista Militar chileno-argentina. En P. Marimán et al j...Escucha Winka...! Cuatro ensayos de Historia Nacional Mapuche y un Epílogo sobre el futuro. Santiago, Lom Ediciones.

Martínez, JL; Martínez, N.; Gallardo, V. (2003) "Rotos, Cholos y Gauchos: la emergencia de nuevos sujetos en el cambio de algunos imaginarios nacionales republicanos (siglo XIX) En Castillo et al Eds. Nación, Estado y Cultura en América Latina. Ediciones Facultad de Filosofía y Humanidades, Universidad de Chile.

Mata, M.C. (2009) Comunicación Comunitaria en Pos de la Palabra y la Visibilidad Social. En Construyendo Comunidades... Reflexiones Actuales Sobre Comunicación Comunitaria. Buenos Aires, La Crujía Editores.

Melucci, A. (2002) Acción Colectiva, Vida Cotidiana y Democracia. México, Colmex.

Mella, E. (2007). Los mapuche ante la justicia. La criminalización de la protesta Indígena en Chile. Santiago, Lom ediciones.

Monasterios, G. (2003). Abya Yala en Internet políticas comunicativas y representaciones de identidad de organizaciones indígenas en el ciberespacio. En Mato D. Coord, Políticas de identidades y diferencias sociales en tiempos de globalización. Venezuela: FACES - UCV. pp.: 303 -330.

Monckeberg, M. O. (2009) Los magnates de la prensa. Concentración de los medios de comunicación en Chile. Santiago, Ramdon House Mondadori editors 
Muzzopappa, E. (2003) Un pasado glorioso. Los mapuche en el discurso del ejército chileno. En Castillo et al Editoras: Nación, Estado y Cultura en América Latina. Ediciones Facultad de Filosofía y Humanidades, Universidad de Chile.

Otazo, J. (2003) Dinámicas de Visibilización y Acceso al Discurso de la Prensa en el Caso Mapuche en Chile. (Tesis Magíster en Ciencias de la Comunicación, Universidad de la Frontera, Temuco).

Penalva, C. y de la Parra, D. (2008, enero-abril). "Comunicación de Masas y Violencia Estructural". Revista Convergencia, Volumen 15, número 0046, Universidad Autónoma del Estado de México, Toluca, México, pp. 17-50.

Pinto, J. (2000) De la Inclusión a la Exclusión. La formación del estado, la nación y el pueblo mapuche. Santiago, Instituto de Estudios Avanzados (IDEA), Universidad de Santiago

Piñuel, J.L. (2002). Epistemología, metodología y técnicas del análisis de contenido. Estudios de Sociolingüística 3 (1), 2002, pp. 1-42.

Polleta, F. (1997) Culture and Its Discontents: Recent Theorizing on Culture and Protest. Sociological Inquiry 67: 431-450.

Reiter, A. (2002). Representaciones Sociales. Buenos Aires Editorial UBA.

Roitman, M. (1996). Formas de Estado y Democracia Multiétnica en América Latina. En González Casanova, P. y Roitman, M. Coords. Democracia y Estado Multiétnico en América Latina. México, Ediciones Ceiich-UNAM. Pp. 37-62.

Ruíz, J. (1996). Análisis de Contenido. En: Metodología de la Investigación Cualitativa. Bilbao, Universidad de Deusto, Bilbao.

Sádaba, M. T. (2001) Origen, Aplicación y Límites de la 'Teoría del Encuadre' (framming) en Comunicación. En Comunicación y Sociedad Vol. XIV, №2, 2001, pp. 143-175.

Sandoval, J. (2007) El diario Austral de La Araucanía y su discurso frente al 'Conflicto Mapuche'. Análisis del caso 'Presos Políticos Mapuche en huelga de hambre. 13 marzo al 14 mayo de 2006. Criminalización y reproducción del racismo. (Tesis Licenciatura Comunicación Social, umanidades, Universidad de La Frontera, Temuco, Chile).

Seguel, A. (2007) Crónicas de desencuentros: Gobierno de Ricardo Lagos versus Movimiento Social Mapuche. En Yañez, N. y Aylwin, J. Eds.: El Gobierno de Lagos, los pueblos indígenas y el 'nuevo trato'. Las paradojas de la democracia chilena. Santiago, Lom ediciones.

Stern, S. (2000). La contracorriente histórica: los indígenas como colonizadores del Estado, siglos XVI a XX". En R. Leticia Coord, Los retos de la etnicidad en los estados-nación del siglo XXI. Ciudad de México, Ciesas y Miguel Ángel Porrúa editor.

Subercaseaux, B. (1999) Chile o una loca historia. Santiago, Lom ediciones.

Sunkel, G. y Geoffroy, E. (2001) La concentración económica de los Medios de Comunicación. Santiago, Lom ediciones.

Svampa, M. (2009) Prólogo. En Korol Ed Argentina, criminalización de la pobreza y de la protesta social. Buenos Aires, Ediciones El Colectivo. 
Taylor, C. (1993). El Multiculturalismo y la Política del Reconocimiento. México, Editorial Fondo de Cultura Económica.

Van Dijk, T. (2009) Dominación Étnica y Racismo discursivo en España y América Latina. Barcelona, Gedisa.

Van Dijk, T. (1997). Racismo y Análisis crítico de los medios. España: Ediciones Paidós.

Villagrán, C. (2014). Radiodifusión Mapuche en Gulumapu (Chile): Apuestas por una acción colectiva comunicacional con fines de autorepresentación social y legitimación política (1990-2010). (Tesis Doctorado Estudios Latinoamericanos, Universidad Nacional Autónoma de México, UNAM).

Wimmer, R. y Dominick, J. (1996). La Investigación Científica de los Medios de Comunicación. Una Introducción a sus Métodos. Barcelona, Bosch Casa Editorial.

Zald, M. (1999) Cultura, Ideología y Creación de Marcos Estratégicos. En: Mc Adam, Mc Carthy y Zald Eds. Movimientos Sociales: Perspectivas Comparadas. Madrid, Istmo.

Zavaleta, R. (1987). El Estado en América Latina. En Autodeterminación. Número 3, julio 1987. 